Mongolian Academy of Sciences
Mongolian Journal of Chemistry
The Institute of Chemistry \& Chemical Technology

\title{
Enzymatic technology for Sea buckthorn oil extraction and its biochemical analysis
}

\author{
D.Munkhbayar ${ }^{1 *}$, J.Ariuntungalag ${ }^{2}$, G.Delgersuuri $^{3}$, D.Badamkhand $^{4}$ \\ ${ }^{1}$ School of Industrial Technology, Mongolian University of Science and Technology, Ulaanbaatar \\ 14191, Mongolia-14191 \\ ${ }^{2}$ Technology Incubator Center, MAS, Peace ave.,Ulaanbaatar 13330, Mongolia \\ ${ }^{3}$ Agribiological school, Mongolian State University of Agriculture, Zaisan, Ulaanbaatar 17024, Mongolia \\ ${ }^{4}$ Institute of Chemistry and Chemical Technology, MAS, Peace ave., Ulaanbaatar13330, Mongolia
}

ARTICLE INFO: Received 16 November 2014; revised 24 November 2014; accepted 03 December 2014

\begin{abstract}
The methods of oil extraction process assisted by enzymes are over the last 50 years an alternative designed to replace traditional methods of extraction using organic solvent. This study presents enzyme-assisted extraction method for oil extraction from Sea Buckthorn berries. Parameters for enzyme-assisted extraction of oil with pectinase were optimized through single-factor. Pectinase dose of $0.5 \%$, extraction time 120 minutes, hydrolysis temperature $55^{\circ} \mathrm{C}$ were found optimum, and maximum oil yield of 5.0-5.1\% was achieved under these conditions, and the recovery of the optimized extraction process was calculated to $95.7-98.0 \%$ based on 5.2\% theoretical oil content of Sea Buckthorn berries. This study presents physico-chemical characteristics of pulp oil, extracted from Sea buckthorn berries by enzymatic process. Physico-chemical analysis of pulp oil gave: refractive index $(1.470)$, density $\left(0.92 \mathrm{~g} / \mathrm{cm}^{3}\right)$, acid value ( $7.8 \mathrm{mg} \mathrm{KOH} / \mathrm{g}$, iodine value $\left(132.0 \mathrm{~g} \mathrm{~J}_{2} / 100 \mathrm{~g}\right)$, peroxide value $(2.0 \mathrm{meq} / \mathrm{kg})$, total carotenoid $(325.0 \mathrm{mg} / 100 \mathrm{~g})$, and total tocopherol $(220.0 \mathrm{mg} / 100 \mathrm{~g})$, respectively. The Sea Buckthorn pulp oil by enzymatic treatment contained palmitoleic (42.5\%), linoleic (11.2\%), linolenic (1.2\%), and oleic acids (12.3\%), and thus showed predominance of unsaturated fatty acids $(70.9 \% \mathrm{w} / \mathrm{w})$ compared to traditional treatment unsaturated acids $(51.2 \%)$.

Keywords: Pectinase, pulp oil, extraction, fatty acid, iodine value
\end{abstract}

\section{INTRODUCTION}

Sea buckthorn (Hippophae rhamnoides, L.) is a hardy, deciduous shrub belonging to the family Elaeagnaceae. It bears yellow to orange berries, which have been used for centuries in Europe and Asia. The natural habitat of sea buckthorn extends widely in China, Mongolia, Russia, Finland, Sweden and Norway [1]. The chemical composition of Sea buckthorn oil varies with growing conditions, locality and variety of Sea buckthorn. Sea buckthorn pulp oil is unique among other vegetable oils having high level of unsaturated fatty acids and phenolic compounds, including phenolic acid, phenolic alcohol and flavonoids. It contains mostly unsaturated fatty acids such as palmitoleic and oleic acid, linoleic acid and linolenic acid, etc $[5,9]$.

Sea Buckthorn seed and pulp oils are considered the most valuable components of the berries comprising a unique fatty acid composition, fat-soluble vitamins, and plant sterols. Oil from the pulp contains more saturated fatty acids than from the seeds and comprises primarily palmitic acid, palmitoleicacid and lower concentrations of other polyunsaturated acids. Among pigments, $\beta$-carotene is the most abundant in the pulp oil and constitutes 15 to $55 \%$ of total amount of carotenoids [10]. Important sterols in Sea buckthorn are cholesterol, phytosterols and steroid hormones, and their contents in seeds, pulp, and fresh whole berries are 1200-1800, 240-400, and 340$520 \mathrm{mg} / \mathrm{kg}$ of berries, respectively [6].

Canadian authors were used enzymes, such as Pectinex Ultra SP-L, Celluclast $1.5 \mathrm{~L}$ and Viscozyme L for oil extraction from the Sea Buckthorn pulp obtained after juice separation. Enzymatic extractions were carried out for 24 hours at $\mathrm{pH} 5.0$ and $50^{\circ} \mathrm{C}$, using five different enzyme concentrations and the average oil yields obtained with Viscozyme $L$ (2.8\%) and Pectinex Ultra SP-L (2.6\%) were significantly higher than those obtained with Celluclast $1.5 \mathrm{~L}$ (2.1\%) [12].

Enzymatic oil extraction technology for the Sea Buckthorn berries is not practically studied in Mongolia .

The objective of this work was to investigate the

* corresponding author: e-mail: dnmunkhbayar@gmail.com 
extraction yields and composition of oils from Sea buckthorn pulp, using Pectinex Ultra SP-L (Pectinase enzymes ).

\section{EXPERIMENTAL}

Materials and Methods: Sea buckthorn berries used for all experiments was obtained from Sea buckthorn Gardens at Batsumber soum of Tuv province, Mongolia. Sea buckthorn berry's proximate composition analysis were conducted in Food Analysis Laboratory of MUST. Oil content was determined by Soxhlet continuous extraction of sample $(5 \mathrm{~g})$ with petroleum ether for 6 hours at solvent boiling point $\left(45\right.$ to $60^{\circ} \mathrm{C}$ ). Nitrogen was analyzed by the Kjeldahl method and protein content was calculated applying the factor (5.3) recommended to fruits. Ash was determined by sample $(3 \mathrm{~g})$ incineration in the muffle furnace at $550^{\circ} \mathrm{C}$ for 5 hours. Sugar content was estimated by Bertrand's method. Iodine value, density, refractive index, acid value, peroxide and iodine values of the traditionally extracted and enzyme-extracted oils were determined using IUPAC standard methods (1992) in the Food Research Laboratory of Japan. The density and refractive index of the oils were determined by Pycnometer (Helium, Accupyc 1330) and Refractometer (RX-7000 $\alpha$ ), respectively. Peroxide value was measured by oil titrating $(0.5 \mathrm{~g})$ with sodium thiosulphate solution. lodine values were determined using Wijs' solution. Tocopherol and total carotenoid were analyzed using a Spectrophotometer (UV 5200, Jinan precision, 190-

Table 1. Chemical composition of Sea buckthorn berries

\begin{tabular}{llll}
\hline № & Parameters & $\begin{array}{l}\text { Observed } \\
\text { value }\end{array}$ & $\begin{array}{l}\text { Reported } \\
\text { value }\end{array}$ \\
\hline 1 & pH & 2.3 & $2.1-2.5$ \\
2 & Protein , \% & 1.2 & $0.8-1.2$ \\
3 & Oil, \% & 5.4 & $2.0-8.0$ \\
4 & Sugar, \% & 6.8 & $3.0-8.6$ \\
\hline
\end{tabular}

$1100 \mathrm{~nm}$ ) following Current Protocols in Food Analytical Chemistry standard methods [8, 10]. The fatty acid composition of the Sea buckthorn pulp oils was analyzed using a High Performance Liquid Chromatograph (Agilent 1200, HPLC-UV) by ISO 18395:2005. This analysis was conducted in Food Research Laboratory of the NIG Gmbh of Germany. Pectinase enzyme as named Pectinex Ultra SP-L (Switzerland) was used for oil extraction process.

Enzyme-assisted oil extraction: For each experiment $100 \mathrm{~kg}$ of Sea buckthorn berries mix was washed and crushed. Crushed berries obtained were heated to $65^{\circ} \mathrm{C}$ for 30 minute and waste (seeds and skin residual mix) and raw juice were separated by decanter centrifuge. Raw juice was submitted to enzymatic treatment in fermentation tanker, for 120 minutes in order to separate oily layer. The enzymatic reaction was carried out with a Pectinex Ultra SP-L enzyme at $55^{\circ} \mathrm{C}$, under agitation. After this step, the mixture was heated at $65^{\circ} \mathrm{C}$ again for 10 minutes to inactivate enzyme. Mixture of juice and oily emulsions was centrifuged at $5000 \mathrm{rpm}$ (disk centrifuge) at $22^{\circ} \mathrm{C}$ during 35 minutes. The procedure resulted in Sea Buckthorn pulp oil, released by enzymatic reaction, which could be then separated from the remaining juices $[3,5,7,11]$.

\section{RESULTS AND DISCUSSION}

Determination of chemical composition of Sea buckthorn berries: We have introduced a chemical composition of Sea buckthorn berries cultivar's mix (Chuiskaya, Obilnaya, Oranjivaya, Belikan, and Ovskaya) before enzymatic treatment (Table 1). The chemical composition of Sea Buckthorn berries like $\mathrm{pH}$, protein, oil, and sugar were determined according to standard procedures as MNS ISO 1842:2000, (MNS 3581:89, and MNS 2546:1997 respectively.

Results of chemical analysis of Sea buckthorn berries indicate the high concentrations of protein, oil and sugar. As results of this, we concluded that provided requirement for Sea Buckthorn berries enzymatic processing.

Effect of enzyme concentration, temperature, $\mathrm{pH}$ and incubation time: The raw juice isolated by decanter centrifuge was submitted to enzymatic treatment in fermentation tanker, in order to separate the oily layer and adjusted to $\mathrm{pH} 4.5$ - the normal $\mathrm{pH}$ of SBT juice. The enzyme solution was tested in three different concentrations $(0.2,0.3$, and $0.5 \%)$ and reaction mixture was incubated for 30-120 minutes at about 45 to $55^{\circ} \mathrm{C}$. The enzyme in the slurry were inactivated by thermal treatment. Oil extraction yields were calculated as the mass ratio percentage of extracted oil to pulp material. Table 2 shows the simultaneous effects of applied Pectinex Ultra SP-L enzyme concentration and incubation time on the oil the oil yield.

Pectinex Ultra SP-L dose of $0.5 \%$, extraction time 120 minutes, hydrolysis temperature $55^{\circ} \mathrm{C}$ were found as optimal. The maximum oil yield of $5.1 \%$ was achieved under these conditions, and the recovery of the optimized extraction process was calculated to $98.0 \%$ based on $5.2 \%$ theoretical oil content of Sea buckthorn berries.

Difference between the enzymatic and traditional treatment on products and residue: We have introduced an enzymatic treatment just after crushing in order to enhance the recovery of juice and run experiments on five cultivars mix harvested from Mongolian central zone (Table 3).

As shown in Table 3, the yield of clear juice $72.5 \mathrm{~L}$ and could be concluded that enzymatic treatment is more 
Table 2. Effect of enzyme concentration and incubation time on oil yield

\begin{tabular}{ccccc}
\hline No & $\begin{array}{c}\text { Pectinex SP-L } \\
\text { concentrations, \% }\end{array}$ & $\begin{array}{c}\text { Enzymatic treatment } \\
\text { temperature, }{ }^{\circ} \mathrm{C}\end{array}$ & Extraction time, min & Oil yield, \% \\
\hline 1 & 0.2 & 45 & 30 & 2.5 \\
2 & 0.3 & 45 & 60 & 3.5 \\
3 & 0.5 & 55 & 120 & 5.1 \\
\hline
\end{tabular}

convenient as traditional treatment technology. Physico-chemical properties of Sea buckthorn pulp oil: We have conducted comparative study of physico -chemical composition of Sea buckthorn berries pulp oils obtained by enzyme-assisted treatment and traditional processing. All pulp oils are characterized by measuring density, acid value, iodine value, total carotenoid, fatty acids composition (Table 4, 5).

It is especially interesting that refractive index and density are highly stable parameters. They seems to be good indicators for purity of oils. As we expected parameters reflecting freshness and oxidative status of oils vary strongly. In theoretical regard the peroxide value gives information about the number of peroxide compounds in the oil and hence of the age and quality of the berry oil.

As shown in Table 4, the peroxide value of oil processed by enzymatic treatment was higher than oil separated by traditional treatment. The determined acid value was higher $(15.0 \mathrm{mg} \mathrm{KOH} / \mathrm{g})$ in the pulp oil in oil obtained by enzymatic treatment (325.0 and $220.0 \mathrm{mg} / 100 \mathrm{~g})$.

Maximum oil yield of $5.1 \%$ was achieved under these conditions, and the recovery of the enzymatic extraction process was calculated to $95.7-98.0 \%$ based on $5.2 \%$ theoretical oil content of Sea buckthorn berry. Finally, enzymatic extractions were conducted on fruit pulp and the fatty acids analysis of this pulp oil has shown that this oil is rich palmitoleic acid (42.5\%), oleic acid (16.0\%) linoleic acid (11.2\%), and lowest linolenic acid (1.2\%) as traditional treatment. Also, in traditional treatment, fatty acids analysis of this pulp oil has shown that high palmitic acid $(35.5 \%)$ stearic acid $(2.8 \%)$, palmitoleic acid (32.0\%), lowest linolenic $(0.9 \%)$ and low linoleic acid (6.3\%). As shown in Table 5, in pulp oil obtained by enzymatic process unsaturated fatty acids occupied $70.9 \%$ of the total fatty acids. The geographical and climatic conditions, as well as cultivating activities, genetic differences among species, maturity stages of

Table 3. Comparison for process development trails using Sea buckthorn berry

\begin{tabular}{clcc}
\hline No & \multicolumn{1}{c}{ Parameters } & Enzymatic treatment & Traditional treatment \\
\hline 1 & Berries, kg & 100 & 100 \\
2 & Raw Juice, L & 85.0 & 65.0 \\
3 & Clear juice, L & 72.5 & 54.0 \\
4 & Solid sludge, kg by wet weight & 25.6 & 23.4 \\
5 & Seed, kg & 4.9 & 3.8 \\
6 & Skin and pulp residual, kg dry weight & 7.5 & 5.0 \\
\hline
\end{tabular}

obtained by traditional treatment compared to enzymatic treatment. In the aggregate, oxidation of oil leads to increasing of acid value because of triglycerides are converted into fatty acids and glycerol upon aging [3]. The overall results in both treatment showed that iodine value was found to higher in pulp oil. lodine value is a measure of degree of the unsaturation or number of double bonds presented in oil. The iodine value of Sea buckthorn pulp oils (132.0 mg $\mathrm{KOH} / \mathrm{g}$ ) obtained by enzymatic treatment was higher than in traditional treatment. The most important are carotenoids and vitamin E, both of which possess important physiological properties[10]. The results of this study reveal that total carotenoid and tocopherol were presented only the berries and oil extraction methods could explain these differences in fatty acid compositions. Differences between the fatty acid compositions of the studied oils could be attributed to the different phases of biosynthesis and accumulation of fatty acids [2]. The concentration of fatty acids in oil extracted from Sea Buckthorn berries was using similar in traditional extraction techniques. In the case of oils, once again the same differences found in the fatty acid composition of oils were observed in the fatty acid fractions, when comparing the two investigated treatment methods. Enzyme-assisted extraction method has shown to be an effective technique to obtain a higher oil yield, fast for oil extraction, and clear juice after oil extraction. 
Table 4. Comparison for physical and biochemical composition of Sea buckthorn pulp oils

\begin{tabular}{clccc}
\hline № & \multicolumn{1}{c}{ Parameters } & Enzymatic treatment & $\begin{array}{c}\text { Traditional } \\
\text { treatment }\end{array}$ & Reported value \\
\hline 1 & Density, $\mathrm{g} / \mathrm{cm}^{3}$ & 0.92 & 0.89 & 0.914 \\
2 & Refractive index, $20^{\circ} \mathrm{C}$ & 1.470 & 1.480 & 1.476 \\
3 & Peroxide value, $\mathrm{meqO}_{2} / \mathrm{kg}$ oil) & 2.0 & 5.0 & 5.0 \\
4 & Acid value, $\mathrm{mg} / \mathrm{KOH} \mathrm{g}$ & 7.8 & 15.0 & $6.4-15.0$ \\
5 & lodine value, $\mathrm{mg} \mathrm{KOH} / \mathrm{g})$ & 132.0 & 120.0 & 124.0 \\
6 & Total carotenoid, $\mathrm{mg} / \mathrm{l00g}$ & 325.0 & 242.0 & - \\
7 & Total tocopherol, $\mathrm{mg} / 100 \mathrm{~g}$ & 220.0 & 120.0 & $70-120$ \\
\hline
\end{tabular}

Table 5. Fatty acids composition of Sea buckthorn pulp oil by HPLC

\begin{tabular}{clccc}
\hline № & Parameters & Enzymatic treatment & Traditional treatment & Reported value \\
\hline 1 & Yield , \% & $5.0-5.1$ & 3.5 & $2.0-6.02$ \\
& & Fatty acids, \% & & \\
2 & Palmitic acid & 27.2 & 35.5 & $28.0-32.0$ \\
3 & Stearic acid & 1.6 & 2.8 & 16.0 \\
4 & Palmitoleic acid & 42.5 & 32.0 & $28.0-54.0$ \\
5 & Oleic acid & 16.0 & 12.0 & Up to 19.0 \\
6 & Linoleic acid & 11.2 & 6.3 & Up to 12.0 \\
7 & Linolenic acid & 1,2 & 0.9 & Up to 5.3 \\
\hline
\end{tabular}

\section{CONCLUSIONS}

Enzyme extraction is a technique that could be applied to obtain Sea Buckthorn pulp oil. Among enzyme used in this study, Pectinex Ultra SP-L gave an oil extraction yield significantly higher (5.1\%) than that attained with traditional treatment. The results pointed to the optimal conditions of Pectinex SP-L concentration of $0.5 \%$, incubation time 120 minutes, and $\mathrm{pH}$ around 4.5 . Fatty acid analysis revealed that palmitoleic acid $(42.5 \%)$, linoleic acid $(11.2 \%)$, and linolenic acid (1.2\%), respectively.

\section{ACKNOWLEDGEMENTS}

The authors wish to thank colleagues of Japan Food Research Laboratories, Shibuya, Tokyo and NIG Gmbh Laboratories, Magdeburg, Germany for chemical analysis.

\section{REFERENCES}

1. Attar Singh Chauhan., Fradeep Singh Negi., Ramesh Shyam Ramteke (2005) Process for preparing antibacterial and antioxidant fraction from Sea buckthorn. US Patent 6946154B2

2. Casmir.C.A., David B.M. (2002) Food lipids: Chemistry, Nutrition, and Technology, 2nd Ed., CRC Press, 910- 916

3. Gunstone F.D. (2002) Vegetables oils in food technology. CRCPress, 41 - 47

4. Kaminskas A., Briedis V., Budronione R., et al. (2006) Fatty acid composition of Sea buckthorn pulp of Lithuanian origin stored at different temperatures. Biologja, 2, 39-41
5. Kang J., Gu J.J, Wang J., Wu T., Zhang L.X. (2011) Enzymatic extraction of Sea buckthorn fruit oil and its fatty acids profile analysis. J. F.ood Sci., doi: R284.1

6. Parmjit S.P., Satwinder S.M., Harish K.C. (2010) Enzymes in Food Processing: Fundamentals and Potential Applications., I. K. Int. Pub. House, 199236

7. Kumar R., Kumar G.P, Ohaurasia O. et al. (2011) Phytochemical and pharmacological profile of Sea buckthorn oil: A Review. Res. J. Med. Plant, doi: 10.3923/rjmp.2011.491.499

8. Ranjith A. (2009) Phytochemical investigation on Sea buckthorn (Hipppophae rhamnoides, L) berries. Dissertation, National Institute for Interdisciplinary Science and Technology.

9. Andersson S.C. (2009) Carotenoids, Tocochromanols and Chlorophylls in Sea Buckthorn Berries (Hippophae rhamnoides) and Rose Hips (Rosa sp.). Dissertation. Swedish University of Agricultural Sciences.

10. Standard methods for Analysis of oils, fats and derivatives: International Union of pure and Applied Chemistry, 7nd Ed., Oxford Press.

11. Rodrigues S., Fernandes F.A.N. (2012) Advances in Fruit Processing Technologies, CRC Press, 235236

12. http://archimede.bibl.ulaval.ca/archimede/ fichiers/24426/apc.html 